\title{
非線形弾性体材料を用いた吸振台につロで(1)
}

西野

宏 $^{(2)}$

\section{On the Shock-Absorber with Non-linear Elastic Materials}

by Hiroshi NISHINO

This report descibes the calculation of the shape and transmissibility of the vibration of the shock-absorber made of rubber or lethers, so-called non-linear elastic materials, in which the spring force is not proportional to the stress.

Using the stress $x$ as variable, the spring force $P$ is approximately represented as follows :$P=n^{2} x+\alpha x^{3}$

When the external force is $A \sin \omega t$, the effect on the transmissibility, owing to the nonlinearity, depends on the term $\alpha \cdot A^{2} / n^{6}$. But the ratio $\omega / n$ is generally high in the shock-absorber, and so that the effect can be ignored.

ゴムまをは革等の復原力がひずみに比例しない非線 形特性を有する弾性体を振動防止装置に用いた場合， 振動の模様ならびに振動の伝達について計算する。こ の上うな材料では変位が大きくなると復原力はもはぬ ひずみに比例せず，やや大きくなる。そこでその復原 力近似的に次式で表わす。

$$
P(x)=n^{2} x+\alpha x^{3}
$$

$P(x)$ は振動系の単位質量当り变位 $x$ 走生じをときの 復原力で女る。、は小さな量である。減﨡力は速度に 比例すると見なせば $c \frac{d x}{d t}$ で表わされる。ここに $c$ 忚 正の定数である.吸振台气の他振動招止装置を施した 機械に，正弦的な振動外力が生ずるとして，それを振 動系の単位質量当り $F \cos \omega t$ で表わせば振動系の運 動方程式は

$$
\ddot{x}+c \dot{x}+n^{2} x+\alpha x^{3}=F \cos \omega t
$$

これを解くのに逐次近似法を用いて

$$
x=x_{1}+x_{2}+\cdots \cdots
$$

そだし $x_{2}$ は $x_{1}$ に対して第 2 位の微小量とする。 近似解として $x_{1}+x_{2}$ までとれば， $x_{1}$ について

$$
\ddot{x}_{1}+c \dot{x}_{1}+n^{3} x_{1}=F \cos \omega t
$$

第 2 位微小量 $x_{2}$ については

$$
\ddot{x}_{2}+c \dot{x}_{2}+n^{2} x_{2}=-\alpha x_{1}^{3}
$$

をそれぞれ解けば $x$ の近似解として

$$
\begin{aligned}
& x \fallingdotseq x_{1}+x_{2}=\frac{F}{\sqrt{c^{2} \omega^{2}+\left(n^{2}-\omega^{2}\right)^{2}}} \cos (\omega t-\varphi) \\
& -\frac{3}{4} \alpha \frac{F^{3}}{\left\{c^{2} \omega^{2}+\left(n^{2}-\omega^{2}\right)^{2}\right\}^{2}} \cos (\omega t-2 \varphi) \\
& \alpha \quad F^{3} \cos \left(3 \omega t-\varphi^{\prime}-\tau^{\prime}\right)
\end{aligned}
$$

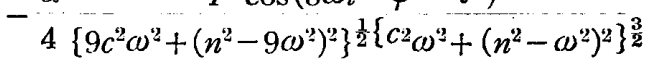

$$
\begin{aligned}
& \text { ここに } \varphi=\tan ^{-1} \frac{c \omega}{n^{2}-\overline{\omega^{2}}}
\end{aligned}
$$

$$
\begin{aligned}
& \varphi^{\prime}=\tan ^{-1} \begin{array}{c}
3 c \omega \\
n^{2}-9 \omega^{2}
\end{array} \\
& \tau^{\prime}=\tan ^{-1}\left\{\frac{c \omega}{n^{2}-\omega^{2}} \times \frac{\left.3\left(n^{2}-\omega^{2}\right)\right)^{2}-c^{2} \omega^{2}}{\left(n^{2}-\omega^{2}\right)^{2}-3 c^{2} \omega^{2}}\right\}
\end{aligned}
$$

を得る，同様にして，更に近似の度を高めることがで， きる。

次に吸振台などの振動防止装置の振動伝達率を求め る.この時の強制振動は (3) で示される上うに単弦振. 動ではないけれども, 定常振動は $\omega$ の振動率を有し ているので头のように表わすことができる。

$$
x=a \sin \omega t+b \cos \omega t
$$

ここに $\boldsymbol{a}, \boldsymbol{b}$ は時間 $\boldsymbol{t}$ の かん数で女る.（3）上りわ かる上うに, $a, b$ の変化は緩慢で岁るから

$$
\begin{array}{ll}
\dot{a} \ll \omega a, & \ddot{a} \ll \omega \dot{a} \\
\dot{b} \ll \omega a, & \ddot{b} \ll \omega \dot{b}
\end{array}
$$

多成立する，この条件を考慮して（4）を（2）に代入 して $\cos \omega t, \sin \omega t$ の係数を比較すると

$$
\begin{aligned}
& \left.2 \frac{d a}{d t}+c a+\frac{n^{2}-\omega^{2}}{\omega} b+\frac{3}{4} \frac{\alpha}{\omega} b\left(a^{2}+b^{2}\right)=\frac{F}{\omega}\right) \\
& 2 \frac{d b}{d t}-\frac{n^{2}-\omega^{2}}{\omega} a+c b-\frac{3}{4} a{ }^{2} a\left(a^{2}+b^{2}\right)=0
\end{aligned}
$$

の連立方程式を得る，最大振幅を与える条件は

$$
\frac{d}{d t}\left(a^{2}+b^{2}\right)=2\left(a \frac{d a}{d t}+b \frac{d b}{d t}\right)=0
$$

でせるから（5）名ら最大振幅として

$$
A=\frac{F}{\sqrt{c^{2} \omega^{2}+\left(n^{2}-\omega^{2}+\frac{3}{4} \alpha A^{2}\right)^{2}}}
$$

を得る。すなわち最大振幅は線形弹性体の場合とくら ベると，非線形項の入，㣽ため幾分小さくなる。この 
振動の安定を調くるために $a, b$ に变化 $\Delta a, \Delta b$ を与 えて，これが時と共に 0 に近ずくか否かを計算する。

$$
\begin{aligned}
& \frac{d a}{d t}=0, \quad \frac{d b}{d t}=0 \cdots \\
& c a+\frac{n^{2}-\omega^{2}}{\omega} b+\frac{3 \alpha}{4} b\left(a^{2}+b^{2}\right)=\frac{F}{\omega} \\
& \left.-\frac{n^{2}-\omega^{2}}{\omega} a+c b-\frac{3}{4} \frac{a}{\omega} a\left(a^{2}+b^{2}\right)=0\right\}
\end{aligned}
$$

の条件のもとに（5）の $a, b に a+\Delta a, b+\Delta b$ をそ れぞれ代大すると結局

$$
\left.\begin{array}{l}
4 \frac{d^{2}(\Delta a)}{d t^{2}}+4 c \frac{d}{d t}(\Delta a)+\left(c^{2}+\gamma^{2}\right) \Delta a=0 \\
4 \frac{d^{2}}{d t^{2}}(\Delta b)+4 c \frac{d}{d t}(\Delta b)+\left(c^{2}+\gamma^{2}\right) \Delta b=0
\end{array}\right\}
$$

を得る. ここに $r=\frac{\dot{n}^{2}-\omega^{2}}{\omega}+\frac{3}{4} \frac{a}{\omega}\left(a^{2}+b^{2}\right)$

(9)に拈いて $c$ は正で䇅るから $\Delta a, \Delta b$ は時間の経過 と共に減袁する。ゆえに（5）を解いて（4）に代入し て得られる振動は安定で女る岁ことがわ名る。

最大振幅の近似計算は头の上うにすればよい。

$$
A_{1}=\frac{F}{\sqrt{c^{2} \omega^{2}+\left(n^{2}-\omega^{2}\right)^{2}}}
$$

これを（6）に代大して

$$
A_{2}=\frac{F}{\sqrt{c^{2} \omega^{2}+\left(n^{2}-\omega^{2}+\frac{3}{4} \alpha A_{1}^{2}\right)^{2}}}
$$

以下このようにして近似度を高めることができる. 以 上の計算は非線形共振の近傍では使用することはでき ない.

振動の際，吸振台を経て基礎台に伝達される力はば ね力と隇衰力の合力でをるが，この二力は（3）斿わ かるように必ずしも $90^{\circ}$ の位相差圭有しないけれど も, 近似的には位相差 $90^{\circ}$ として取り扱い得る.か人 して計算される振動伝達率は真の振動伀達率よりも若 干, 大きくなる。

合力の最大値は

$$
F^{\prime} \fallingdotseq A \sqrt{\left(n^{2}+\alpha A^{2}\right)^{2}+c^{2} \omega^{2}}
$$

強制力の最大值は $F$ でをり $F$ と $F^{\prime}$ の比,すなわち 伝達力は, 結局

$$
\varepsilon=\sqrt{\frac{1+\left(\frac{n^{2}+\alpha A^{2}}{c \omega}\right)^{2}}{1+\left(\frac{n^{2}-\omega^{2}+\frac{3}{4} \alpha A^{2}}{c \omega}\right)^{2}}}
$$

すなわち伝達率は振幅により異なってくる、を索計算 するには近似值として

$$
A_{1}=\frac{F}{c \omega \sqrt{1+\left(\begin{array}{c}
n^{2}-\omega^{2} \\
c \omega
\end{array}\right)^{2}}}
$$

求め，これ道（10）に代入すれば上い。たたしこれ
は共馛点の近傍では用いられない，計算を容易にする 怘めに臨界減裳係数

$$
c_{c}=2 n
$$

起用いて $A_{1}$ 乾よび $\varepsilon$ 求めると

$$
\begin{aligned}
& A_{1}=\frac{F}{n^{2} \sqrt{\left(1-\frac{\omega^{2}}{n^{2}}\right)^{2}+4\left(\frac{c}{c_{c}} \frac{\omega}{n}\right)^{2}}} \\
& \varepsilon=\left\{\begin{array}{l}
4\left(\frac{c}{c_{c}} \frac{\omega}{n}\right)^{2}+\left(1+\frac{\alpha A_{1}^{2}}{n^{2}}\right)^{2} \\
4\left(\frac{c}{c_{c}} \frac{\omega}{n}\right)^{2}+\left(1-\frac{\omega^{2}}{n^{2}}+\frac{3}{4} \frac{\alpha A_{1}^{2}}{n^{2}}\right)^{2}
\end{array}\right\}^{\frac{1}{2}}
\end{aligned}
$$

\begin{tabular}{|c|c|c|c|c|c|}
\hline$\frac{c}{c c}=0.1$ & $\begin{array}{l}a F^{2} / n^{6} \\
\omega / n\end{array}$ & 0 & $0^{\circ} 2$ & 0.5 & $1^{\circ} 0$ \\
\hline & $\begin{array}{l}1 \cdot 5 \\
1 \cdot 75 \\
2 \cdot 0 \\
2 \cdot 25 \\
2 \cdot 5 \\
3 \cdot 0 \\
3 \cdot 5\end{array}$ & $\begin{array}{l}0.812 \\
0.515 \\
0.356 \\
0.268 \\
0.212 \\
0.145 \\
0.110\end{array}$ & $\begin{array}{c}(0.970) \\
0.535 \\
0.366 \\
0.279 \\
0.214 \\
0.146 \\
0.110\end{array}$ & $\left(\begin{array}{c}(1 \cdot 249) \\
0.582 \\
0.377 \\
0.295 \\
0 \cdot 217 \\
0 \cdot 147 \\
0 \cdot 110\end{array}\right.$ & $\begin{array}{c}(1 \cdot 918) \\
0.657 \\
0 \cdot 400 \\
0.324 \\
0.219 \\
0.148 \\
0 \cdot 110\end{array}$ \\
\hline$\frac{c}{c c}=0.25$ & $\alpha / n$ & 0 & 0.2 & 0.5 & $1^{\circ} 0$ \\
\hline . & $\begin{array}{l}1 \cdot 5 \\
1 \cdot 75 \\
2 \cdot 0 \\
2 \cdot 25 \\
2 \cdot 5 \\
3 \cdot 0 \\
3 \cdot 5\end{array}$ & $\begin{array}{l}0.857 \\
0.592 \\
0.447 \\
0.358 \\
0.298 \\
0.221 \\
0.176\end{array}$ & $\left(\begin{array}{c}(0.948) \\
0.598 \\
0.454 \\
0.360 \\
0.299 \\
0.221 \\
0.176\end{array}\right.$ & $\begin{array}{c}(1 \cdot 100) \\
0.647 \\
0.464 \\
0.363 \\
0.300 \\
0.222 \\
0.176\end{array}$ & $\begin{array}{c}(1 \cdot 400) \\
0 \cdot 704 \\
0 \cdot 481 \\
0 \cdot 369 \\
0 \cdot 302 \\
0 \cdot 224 \\
0 \cdot 176\end{array}$ \\
\hline
\end{tabular}

となる.ここに

$$
\frac{\alpha A_{1}^{2}}{n^{2}}=\frac{\alpha \frac{F^{2}}{n^{6}}}{\left(1-\frac{\omega^{2}}{n^{2}}\right)^{2}+4\left(\frac{c}{c_{c}} \frac{w}{n}\right)^{2}}
$$

$\frac{\alpha A_{1}^{2}}{n^{2}}, \frac{\alpha F^{2}}{n^{6}}$ は共に次元さ持㤂ない，数値計算の变数 として $\frac{\omega}{n}, \frac{c}{c_{c}}, \alpha \frac{F^{2}}{n^{6}}$ 至取る. 吸振台などの振動防止 装置では $\frac{\omega}{n}$ は 1 より相当大きく，共鳴点から離れた 振動でをるので以上のような近似計算は可能で女る。 振動が非䠌形でなく，線形でするときは $\alpha=0$ とすれ ばよい，減衰のない振動のときは $c=0$ となる。

計算結果は表に示してをる。

振動伝澾率 $\varepsilon$

\begin{tabular}{l|c|c|c|c|c}
\hline$\frac{c}{c_{c}}=0$ & $\alpha F^{2} / n^{6}$ & 0 & 0.2 & 0.5 & $1 \cdot 0$ \\
\hline \multicolumn{1}{c|}{} & 1.5 & 0.800 & $(0.865)$ & $(0.990)$ & $(1.299)$ \\
& 1.75 & 0.485 & 0.516 & 0.565 & 0.653 \\
2.0 & 0.333 & 0.335 & 0.338 & 0.343 \\
2.25 & 0.245 & 0.249 & 0.255 & 0.261 \\
& 2.5 & 0.190 & 0.191 & 0.191 & 0.191 \\
& .0 & 0.125 & 0.125 & 0.125 & 0.125 \\
& 3.5 & 0.089 & 0.089 & 0.089 & 0.089 \\
\hline
\end{tabular}




\begin{tabular}{l|c|c|c|c|c}
\hline$\frac{c}{c c}=0.5$ & $a F^{2} / n^{6}$ & 0 & 0.2 & 0.5 & 1.0 \\
\hline & $\omega / n$ & & & & \\
\hline & 1.5 & 0.923 & $(0.950)$ & $(0.983)$ & $(1.063)$ \\
1.75 & 0.694 & 0.709 & 0.728 & 0.773 \\
& 2.0 & 0.620 & 0.624 & 0.629 & 0.639 \\
& 2.25 & 0.530 & 0.531 & 0.535 & 0.538 \\
2.5 & 0.463 & 0.464 & 0.465 & 0.467 \\
& 3.0 & 0.370 & 0.370 & 0.371 & 0.371 \\
& 3.5 & 0.308 & 0.308 & 0.308 & 0.310 \\
\hline
\end{tabular}

表中, カッコを附しをものは, 非線形共振の近傍で せって，近似計算の適用できないことを示している。 以上の計算結果より次のことがわかる、ばねの復原力 s;

$$
P(x)=n^{2} x+a x^{3}
$$

で表わされるときは振動が非線形でする゙るために，吸振
台の伝達率に抢よほす影響は保数 $\alpha$ に比例し，強制 外力の大きさの二乗に比例し， $n^{2}$ の三乗に逆比例す る.すなわち振動系の第 1 近似解の自由振動数に相当 する振動率 $n$ ダ小さいとき, 非線形の影響は最も著 しい. 外部強制力振動率と $n$ との比が増加するにつ れて非線形項の影響は小さくなる。粘性減衰も大きく 外部強制力振動率 $\omega$ と $n$ との比を大きいときは非線 形項の影響は見えない。

一般に吸振台においては $\omega / n$ が大きいから，非線 形項の影響は実際には無視できる。

注: -

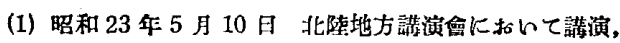
原稿受付 昭和25年7月21日.

(2) 证員, 東海大學.

$621-272.31: 534.121 .1 .014$

\section{蝶面飞摩擦を件つた板ばねの振動(1)}

高橋 敏 雄(2)

\section{Vibrations of Plate Springs with Solid Friction Damping at their Ends}

\section{by Tosio TAKAHASHI}

On vibrations with solid friction damping there are Den Hartog's essays and the others, but these essays treat only the case that frictional forces are constant during the vibrations. On the contrary, as one of the cases that the frictional forces vary with the motion, the author investigated theoretically and experimentally the free and forced vibrations of plate springs "consisted of one sheet with solid friction damping at their ends.

The plate springs are circular arc shapes, the curvatures of which are comparatively large and the thicknesses are very small compared with the radii.

The frictional forces consist in the return forces, the characteristic return force curve has two natural frequencies and the free and forced vibrations which are acted upon by a periodic disturbing force were solved theoretically.

On the experimental measurements of the vibrations, models of the plate spring were made and the vibrations were measured by electro-magnetic ocsillograph. And the results of the experiment agreed with the calculations by the theory.

\section{1. 緒言}

固体摩擦を伴っ天振動に関しては Den Hartogを はじめとしてその他の論交があるがそのいずれもが摩 摖抵抗力が浱動中一定の場合でをる。著者はこの摩摖 抵抗力が浱動中変動する一つの例として端面に摩擦抵 抗をうける一枚の板ばねの振動についてその自由振動 と強制振動を理論訐算と，実験の両直上り研究した。

\section{2. 板ばね作用するカと 、たわみとの関係}

板ばねの形状は第 1 図に示すごとく1枚の板ばねで

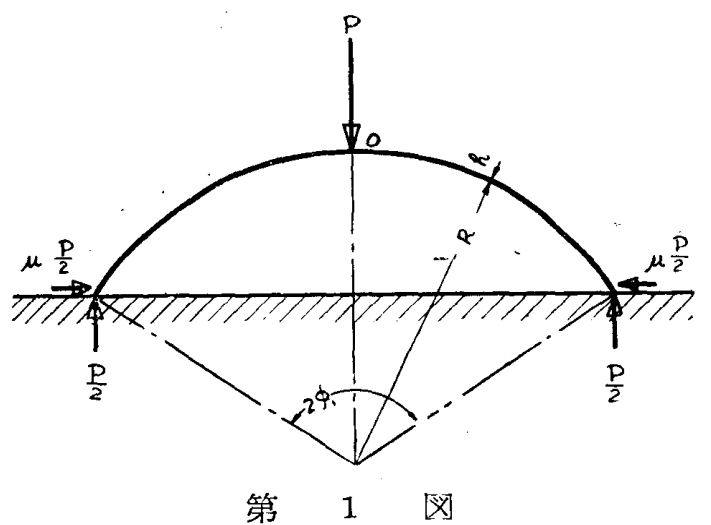

比較的大きな曲率をも，た半径 $R$ の円弧ばねとする。 